\title{
Early immune outcome of retroperitoneal laparoscopic radical nephrectomy for localized renal cell carcinoma: a prospective, randomized study
}

\author{
Yang Lu, MD; Fan Tianyong, MD; Wei Qiang, MD; Cui Xiaobo, MD; Bu Siyuan, MD; Han Ping, MD
}

Department of Urology, West China Hospital, Sichuan University, Chengdu, China

Cite as: Can Urol Assoc J 2012;6:E242-E248. http://dx.doi.org/10.5489/cuaj.11003. Epub 2011 Nov 2.

\section{Abstract}

Objectives: We evaluated differences in cytokine responses and T-lymphocyte subsets following retroperitoneal laparoscopic and conventional open radical nephrectomies for localized renal cell carcinoma (RCC).

Methods: A total of 62 patients with $T_{1} N_{0} M_{0}$ staged RCC were randomized to either retro-laparoscopic $(n=31)$ or open $(n=31)$ radical nephrectomy. Plasma levels of interleukin-1 $\beta$ (IL-1 $\beta$ ), IL-6, and tumour necrosis factor-alpha (TNF- $\alpha$ ) were measured separately by enzyme linked immunosorbent assay (ELISA) preoperatively and on postoperative days 1 and 5 . Levels of $\mathrm{CD}^{+}, \mathrm{CD}^{+}$and $\mathrm{CD}^{+}$ as well as the $\mathrm{CD}^{+}: \mathrm{CD}^{+}$ratio were acquired by flow cytometry at the same time points.

Results: Levels of IL-1 $\beta$, IL-6 and TNF- $\alpha$ increased significantly compared to preoperative values in both groups $(p<0.05)$ on postoperative day 1 , and all the parameters in the open group were significantly higher than those in the retro-laparoscopy group $(p<0.05)$. On postoperative day 1 , the levels of $\mathrm{CD}^{+}$and $\mathrm{CD}^{+}$and the $\mathrm{CD}^{+}: \mathrm{CD}^{+}$ratio decreased markedly compared to preoperative values for both groups $(p<0.05)$. Elevations of the $\mathrm{CD}^{+}: \mathrm{CD}^{+}$ratio in the retro-laparoscopy group $(p<0.05)$ and the $\mathrm{CD}^{+}$level in the open group $(p<0.05)$ were observed when compared with the other group. On postoperative day 5, the levels of $\mathrm{CD}^{+}$and $\mathrm{CD}^{+}$and the $\mathrm{CD}^{+}: \mathrm{CD}^{+}$ratio in the retro-laparoscopy group, as well as the level of $\mathrm{CD}^{+}$in the open group, returned to about preoperative levels $(p<0.05$ ). Follow-up ranged from 4 to 14 months postoperatively in all 62 patients with a $100 \%$ cancerspecific survival rate in both groups.

Conclusions: Retroperitoneal laparoscopic radical nephrectomy is associated with the milder cytokine responses caused by trauma and inflammation and the better preserved distribution of T-lymphocytes.

\section{Introduction}

Since Clayman and colleagues in $1991^{1}$ reported the first laparoscopic radical nephrectomy (LRN) for a tumour-bearing kidney, this technique has become increasingly popular because of milder postoperative pain, decreased hospital stay and shortened convalescence compared to the conventional open radical nephrectomy $(\mathrm{ORN})$. During the last 20 years, with advances in instrumentation and surgeon experience, LRN has emerged as an equally effective and minimally morbid surgical alternative to ORN for selected kidney neoplasms. ${ }^{2,3}$

Surgical trauma provokes a variety of physiologic and immunologic changes in the host. The host's acute phase response to injury includes a complicated interaction among the metabolic, neuroendocrine and immune systems. This response is deemed to be proportional to the extent of the initial injury and is presumably directed toward the host defense. ${ }^{4}$ Due to this altered immune response in the postoperative period, surgical trauma can cause an increased production of pro-inflammatory cytokines and an inhibition of cellular responses. ${ }^{5} \mathrm{~A}$ wealth of studies with intermediate to long-term follow-up results indicate that laparoscopic radical malignance resections offer equivalent safety and oncologic efficacy as compared to open surgical approaches. ${ }^{6,7}$ This is partially because of the reduced inflammatory response and minimal extent of immunosuppression. However, some authors have reported no evidence of improved immunity after laparoscopy. ${ }^{8-11}$ In addition, port site metastases (PSM) and local recurrences, although occasionally observed, remain a disputable problem with laparoscopic surgery for cancer. ${ }^{12,13}$ With respect to renal cell carcinoma (RCC), laparoscopy related studies on the host immunity are insufficient and incomplete. Whether and how the laparoscopy under $\mathrm{CO}_{2}$ pneumoperitoneum could exert some negative influences on the RCC patients is still unclear. Therefore, it is of great value to compare the immune response following laparoscopic nephrectomy and the open technique. 
In this study, we have directly compared the cytokine responses and variations of T-lymphocyte subsets in blood, as well as the follow-up following LRN and ORN for localized RCC, particularly with a retroperitoneal approach.

\section{Material and methods}

\section{Study design}

A well-established formula was used to calculate the sample size. ${ }^{14,15}$ Our centre accepts about 100 cases of $\mathrm{T}_{1} \mathrm{~N}_{0} \mathrm{M}_{0}$ staged RCC patients in a single year. Except for the candidates for nephron-sparing surgery (NSS), about $60 \%$ patients undergo the radical nephrectomy. Our centre was an appropriate location for our study. As a result, 62 patients with $\mathrm{T}_{1} \mathrm{~N}_{0} \mathrm{M}_{0}$ staged RCC admitted for surgery between January 2009 and January 2010 were included in the study. The diagnosis of RCC was assumed when the colour Doppler imaging, enhanced computed tomography and/or magnetic resonance imaging demonstrated renal masses. Thirty-one patients were randomized to the retro-laparoscopic nephrectomy and an additional 31 patients to the open retroperitoneal technique. The primary clinical parameters were demographic data, tumour information, operating procedure duration, estimated blood loss, duration of hospital stay, complications and follow-up (Table 1). Consequently, all the tumours removed were pathologically confirmed to be RCC. The histological subtype and Fuhrman grade were detailed (Table 1).

The primary endpoints of the study were to demonstrate differences in early immune outcome by evaluating cytokine responses (interleukin-1 $\beta$, interleukin-6, and TNF- $\alpha$ ) and T-lymphocyte subsets in both groups of patients within 5 days postoperatively. Additionally, we had planned to keep close contact with the patients for 5 years to study the results after laparoscopic or open nephrectomy.

The design and execution of this study was approved by the Hospital Ethics Committee, and written informed consent was obtained from every patient.

\section{Exclusion criteria}

Criteria for exclusion included history of infection in the retroperitoneal space, history of hormone replacement or immunosuppression therapy, and previous surgery or trauma to the lumbar part. Any evidence of an acute phase reaction, such as leukocytosis or various fever grades, was also considered an exclusion criterion. Candidates for nephron-sparing surgery (NSS) were also not involved in this research. Other than the NSS candidates, the size of tumours over $4 \mathrm{~cm}$, and mass sizes below $4 \mathrm{~cm}$, but located inside the kidney or adjacent to the hilum were included in this research.

\section{Operations and techniques}

General anesthesia methods and a lateral decubitus position were applied in both groups. For open access, a 20-cm transretroperitoneal 12th rib lumbar incision was done, with no notable details. Retro-laparoscopic operations were performed with a standardized technique using three trocars on the waist. The carbon dioxide pneumoperitoneum was established with an intra-abdominal pressure of 12 to $15 \mathrm{mmHg}$ throughout the operation. Electric scalpel and ultrasound scalpel were used to mobilize the kidney and Hemolock clips were used to ligate the vessels. After complete removal, the intact kidney, with its perirenal fat and fascia, was extracted in an entrapment bag through the 7-cm enlarged incision of the main trocar site, and one F14 drainage tube was secured through the 5-mm trocar site.

\section{Laboratory assays}

Ten milliliters of venous blood sample was taken from each patient by peripheral venipuncture a day before the operation and on days 1 and 5 after the operation.

After collection, $5 \mathrm{~mL}$ of the sample was cooled at room temperature for 30 minutes and centrifuged at $3000 \mathrm{~g}$ for 10 minutes. The serum from the upper layer of the centrifuged blood was separated and stored at $-70^{\circ} \mathrm{C}$ until the analysis started. Concentrations of IL- $1 \beta$, IL- 6 and TNF- $\alpha$ were determined using commercially available enzymelinked immunosorbent assay (ELISA) kits (Bender Med Systems, Vienna, Austria). Each serum sample was tested in duplicates. The sensitivity of the ELISA was $0.3 \mathrm{pg} / \mathrm{mL}$ for IL-1 $\beta, 1.4 \mathrm{pg} / \mathrm{mL}$ for IL- 6 and $1.5 \mathrm{pg} / \mathrm{mL}$ for TNF- $\alpha$.

An additional $5 \mathrm{~mL}$ of the whole blood sample was analyzed to test the T-lymphocyte subsets by two-colour analysis $\left(\mathrm{FI}_{1}-\mathrm{Fl}_{2}\right)$ using a FACSCAN flow cytometer (Becton Dickinson, San Jose, CA) immediately after collection. All monoclonal antibodies were purchased from Becton Dickinson Immunocytometry System: anti-T3-FITC (Leu4), anti-T4-PE (Leu3a) and anti-T8-PE (Leu2a). Data from the whole blood samples were acquired with the automatic SIMULSET Software (Becton Dickinson, San Jose, CA).

\section{Statistical analysis}

Statistical analysis was performed using the SPSS software package 16.0 (SAS Institute Inc., Cary, NC). The independent samples t test was used to compare means between two groups, and the Chi-squared test was for enumeration data. Comparisons between the cytokines and the T-cell subsets before or after surgery were performed according to the analysis of variance (ANOVA) test (single factor factorial; one repeated measure). A value of $p<0.05$ was considered statistically significant. The power was set to 0.9. 
Lu et al.

\section{Results}

Gender, age, weight, body mass index, involved side of kidney, tumour size, histological subtype, Fuhrman grade, procedure duration and main complications were similar in the two groups $(p>0.05)$. Two intraoperative complications were noted respectively in each group, and one wound infection occurred in the open group. The retro-laparoscopy group had advantages over the open group in regards to estimated blood loss (mean $30.0 \pm 18.0$ vs. $156.4 \pm 45.7 \mathrm{~mL}$; $p=0.011$, postoperative gastrointestinal tract (GIT) restoration (mean $18.7 \pm 8.4$ vs. $39.8 \pm 9.1 \mathrm{~h} ; p=0.035$ ), and ambulatory (mean $24.6 \pm 9.3$ vs. $47.7 \pm 10.2$ hours; $p=0.044$ ) and duration of hospital stay after surgery (mean $4.7 \pm 0.9$ vs. $8.0 \pm 1.2$ days; $p=0.019$ ) (Table 1 ).

\section{Cytokine response}

Concentrations of IL-1 $\beta$, IL- 6 and TNF- $\alpha$ measured before the surgery did not differ significantly between the two groups $(p=0.800, p=0.680, p=0.969)$; however, on postoperative day 1 , each group exhibited a noticeable increase in IL-1 $\beta$, IL-6 and TNF- $\alpha$ levels $(p<0.05)$, and all the parameters in the open group were significantly higher than those in the retro-laparoscopy group ( $p=0.035, p=0.007, p=0.008$ ). All values dropped to the preoperative levels on postoperative day 5 , while levels in the retro-laparoscopy group were seemingly closer to the baseline (Fig. 1).

\section{T-lymphocyte subsets}

$\mathrm{CD}^{+}, \mathrm{CD}^{+}$and $\mathrm{CD}^{+}$levels, as well as the $\mathrm{CD}^{+}: \mathrm{CD}^{+}$ratio, were similar for both groups at baseline $(p=0.875, p=0.627$, $p=0.658, p=0.732$ ). On postoperative day 1 , the levels of $\mathrm{CD}^{+}, \mathrm{CD}^{+}$and the $\mathrm{CD}^{+}: \mathrm{CD}^{+}$ratio decreased significantly compared to preoperative values in the two groups $(p<0.05)$. The $\mathrm{CD}^{+}: \mathrm{CD}^{+}$ratio in the retro-laparoscopy group was significantly higher than in open group $(p=0.007)$; furthermore, the level of $\mathrm{CD}^{+}{ }^{+}$in the open group was markedly higher than in the retro-laparoscopy group $(p=0.035)$. On postoperative day 5 , the levels of $\mathrm{CD}^{+}, \mathrm{CD}^{+}$and the $\mathrm{CD}^{+}: \mathrm{CD}^{+}$ratio in the retro-laparoscopy group and $\mathrm{CD}^{+}$level in the open group nearly returned to the preoperative levels $(p>0.05)$. The levels of $\mathrm{CD}^{+}, \mathrm{CD}^{+}$and the $\mathrm{CD}^{+}: \mathrm{CD}^{+}$ratio in the open group remained lower than those in the retro-laparoscopy group ( $p=0.043, p=0.048, p=0.004$ ) (Fig. 2).

\begin{tabular}{|c|c|c|c|}
\hline Variable & Retro-laparoscopy ( $n=31$ ) & Open $(n=31)$ & Significance \\
\hline Gender; no. (\%) & & & $p=0.833$ \\
\hline Male & $19(61.3 \%)$ & $18(58.1 \%)$ & \\
\hline Female & $12(38.7 \%)$ & $13(41.9 \%)$ & \\
\hline Age (years) & $56.2 \pm 10.9$ & $58.1 \pm 11.5$ & $p=0.846$ \\
\hline Weight (kg) & $61.5 \pm 10.7$ & $62.9 \pm 12.3$ & $p=0.889$ \\
\hline Body mass index $\left(\mathrm{kg} / \mathrm{m}^{2}\right)$ & $24.7 \pm 3.4$ & $25.1 \pm 3.3$ & $p=0.891$ \\
\hline Tumour size $(\mathrm{cm})$ & $3.7 \pm 2.1$ & $3.9 \pm 2.2$ & $p=0.915$ \\
\hline Involved side; no. (\%) & & & $p=0.850$ \\
\hline Left & $17(54.8 \%)$ & $16(51.6 \%)$ & \\
\hline Right & $14(45.2 \%)$ & $15(48.4 \%)$ & \\
\hline \multicolumn{4}{|l|}{ Histological subtype } \\
\hline Clear & $23(74.2 \%)$ & $24(77.4 \%)$ & \\
\hline Papillary & $3(9.7 \%)$ & $4(12.9 \%)$ & \\
\hline Chromophobe & $2(6.5 \%)$ & $2(6.5 \%)$ & \\
\hline Others & $3(9.7 \%)$ & $1(3.2 \%)$ & \\
\hline \multicolumn{4}{|l|}{ Fuhrman grade } \\
\hline I & $4(12.9 \%)$ & $6(19.4 \%)$ & \\
\hline II & $13(41.9 \%)$ & $12(38.7 \%)$ & \\
\hline III & $12(38.7 \%)$ & $10(32.3 \%)$ & \\
\hline IV & $2(6.5 \%)$ & $3(9.7 \%)$ & \\
\hline Procedure duration (min) & $109.8 \pm 43.1$ & $101.6 \pm 34.2$ & $p=0.809$ \\
\hline Estimated blood loss (mL) & $30.0 \pm 18.0$ & $156.4 \pm 45.7$ & $p=0.011$ \\
\hline Gastrointestinal tract restoration (h) & $18.7 \pm 8.4$ & $39.8 \pm 9.1$ & $p=0.035$ \\
\hline Ambulatory (h) & $24.6 \pm 9.3$ & $47.7 \pm 10.2$ & $p=0.044$ \\
\hline Hospital stay $(d)$ & $4.7 \pm 0.9$ & $8.0 \pm 1.2$ & $p=0.019$ \\
\hline Main complications & $2(6.5 \%)$ & $3(9.7 \%)$ & $p=0.911$ \\
\hline Follow-up (months) & $9.3 \pm 3.3$ & $9.1 \pm 3.0$ & $p=0.899$ \\
\hline
\end{tabular}




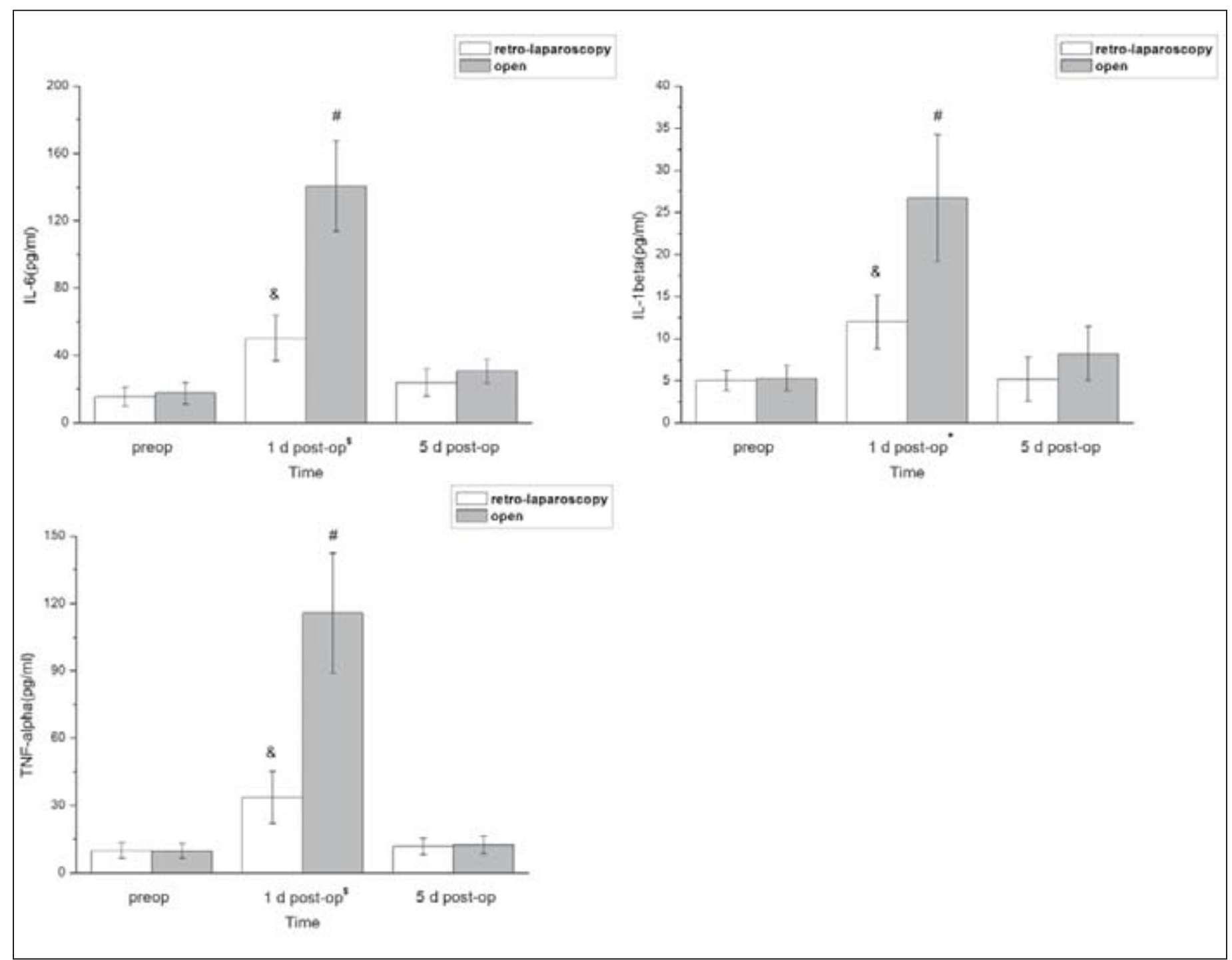

Fig. 1. Increase of serum IL-6, IL-1 $\beta$, and TNF- $\alpha$ after retro-laparoscopic and open radical nephrectomy. ${ }^{8} \pi<0.05$, ${ }^{*} \pi<0.01$ : versus preoperative serum levels; ${ }^{*} \pi<0.05$ : retro-laparoscopy versus open procedure.

\section{Follow-up}

The doctor and each patient remained in close contact. Both groups experienced the same follow-up duration (mean $9.3 \pm 3.3$ vs. $9.1 \pm 3.0$ months; $p=0.899$ ); this followup ranged from 4 to 15 months postoperatively for the 62 patients, with $100 \%$ cancer specific survival rate. No clinical manifestations of any port site, wound or distant metastases or local recurrence were observed and the objective auxiliary imaging examinations further confirmed these results. At the time of this writing, there still has not been any difference in the oncological results for the two groups.

\section{Discussion}

Along with the growing number of incidentally diagnosed kidney neoplasms due to the increased use of imaging procedures, significant advances in the treatment of patients with RCC have been developed during the last 20 years. Laparoscopy is considered safe and reliable to treat various diseases, including malignancies, such as RCC. This minimally invasive surgical technique brings patients milder pain, shorter convalescence and improved cosmesis, moreover, it potentially provides better immunity preservation. ${ }^{6,14}$ However, some oncological risks in laparoscopic surgery for RCC, such as port site metastases and local recurrences, have been reported. ${ }^{16,17}$ These issues concern some scholars.

Any surgical procedure impairs homeostasis and provokes various hemodynamic, metabolic and immunologic 


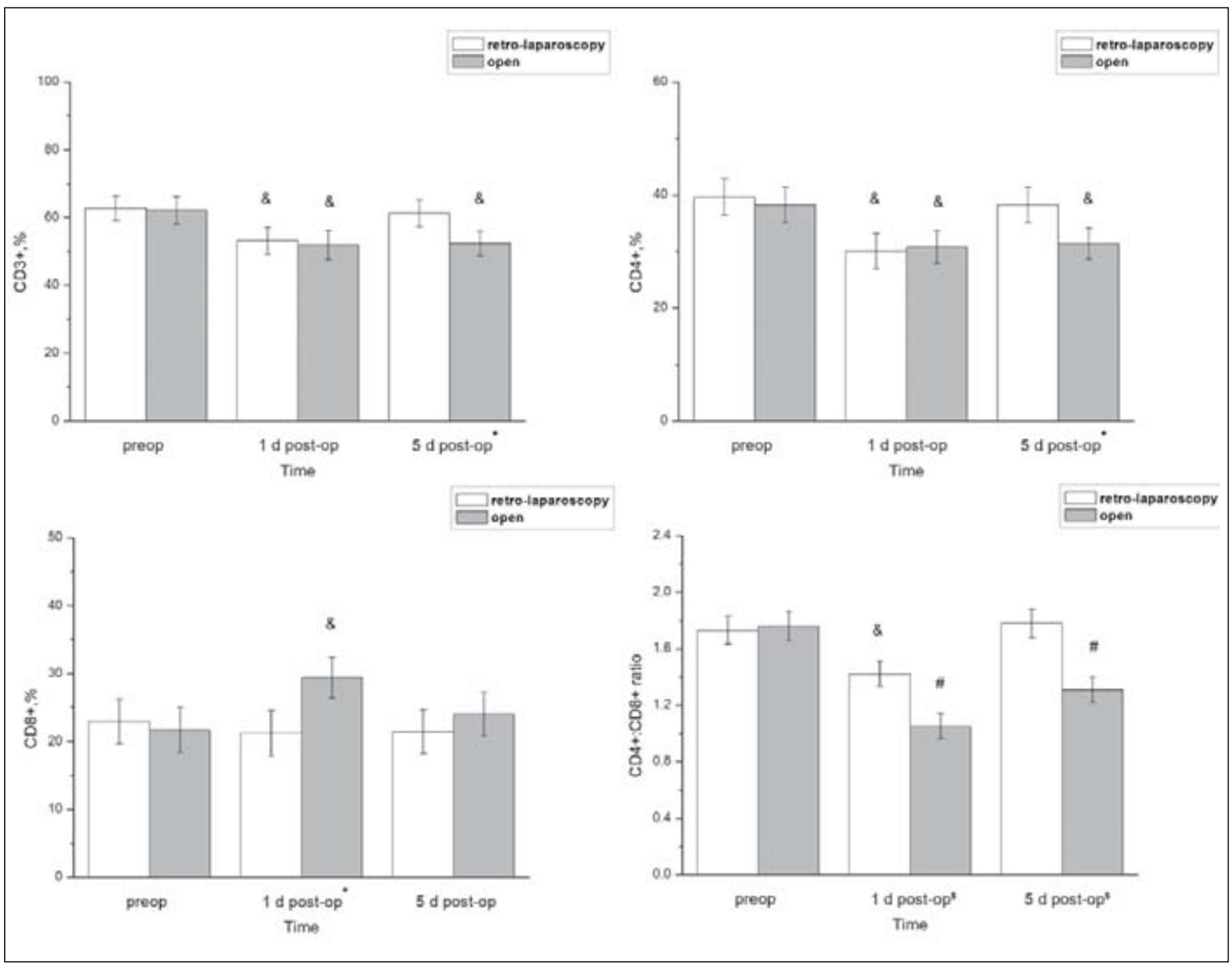

Fig. 2. Variations of $\mathrm{CD}^{+}, \mathrm{CD}^{+}, \mathrm{CD} 8^{+}$, and $\mathrm{CD} 4^{+}: \mathrm{CD} 8^{+}$ratio after retro-laparoscopic and open radical nephrectomy. ${ }^{\&} \pi<0.05,{ }^{*} \pi<0.01$ : versus preoperative serum levels; " $\pi<0.05$ : retro-laparoscopy versus open procedure.

reactions that contribute to host defense. ${ }^{18}$ However, an exaggerated response to injury may result in immunosuppression, which possibly causes infectious complications and tumour metastases resulting in increased postoperative morbidity and mortality. ${ }^{19}$ Laparoscopic surgery may induce less surgical trauma than conventional open procedures due to the lesser extent of injury. Many investigators have found that relatively wound-limiting interventions, such as a laparoscopic cholecystectomy for benign lesions or a laparoscopic total mesorectal excision (TME) for a malignant tumour, ${ }^{20,21}$ are associated with a tempered systemic inflammatory response and better preservation of the postoperative immune function when compared to open techniques. Decreased postoperative pain and fast functional recovery in laparoscopic patients may also be attributed to the reduced inflammatory response and minimal immunosuppression.
Alterations in cytokine production mark the initiation of the acute phase reaction in response to surgical trauma. ${ }^{22}$ Some cytokines, which seem to be beneficial at low circulating levels as immunmodulators, relate to patient deterioration and death when present in large quantities. Currently, the most influential and widely investigated are IL- 6, IL-1 $\beta$ and TNF- $\alpha$.

Interleukin-6 is a pleiotropic pro-inflammatory cytokine whose functions include the control of cellular metabolic activities. ${ }^{23,24} \mathrm{IL}-6$, after acute injury, primarily regulates the hepatic components of the immune response and affects the production of acute-phase proteins, such as haptoglobin, fibrinogen, $\mathrm{C}$-reactive protein (CRP) and alpha-1-antitryp$\sin .{ }^{23}$ Plasma concentrations of IL-6 correlate with operative time, blood loss and degree of tissue trauma. An initial increase in plasma levels of IL-6 is evoked within 1 to 3 
hours of the event, and elevated levels last for 2 to 3 days postoperatively. ${ }^{23}$ Prolonged and excessive IL-6 elevation has been demonstrated to be prospectively related to subsequent clinical deterioration in patients with increased morbidity and mortality, especially for malignancies. ${ }^{24}$ However, some researchers report conflicting results. A laparoscopic nephrectomy was found to cause lower postoperative serum IL-6 levels when compared with an open procedure. ${ }^{25}$ In contrast, Landman and colleagues were unable to confirm this finding. ${ }^{26}$ In our study, increased levels of IL-6 were observed after both types of surgeries, while values in the retro-laparoscopy group were markedly lower than the comparative open group. On postoperative day 5, levels of IL-6 had decreased to baseline in both groups, while the levels remained slightly elevated in the open group. This finding corresponds with previous studies. ${ }^{23,25}$

A number of non-hepatic manifestations of the acute inflammatory response, such as fever, tachycardia and leukocytosis, have been attributed to the release of IL-1 $\beta$ and TNF- $\alpha .{ }^{24}$ These cytokines play a pivotal role in initiating a cascade of inflammatory mediators and the subsequent activation of leukocytes, lymphocytes and mononuclear cells to perform the cell-mediated immune response. ${ }^{27}$ Glaser and colleagues reported that levels of IL-1 $\beta$ during and after conventional cholecystectomies were significantly higher than those during and after laparoscopic procedures..$^{28} \mathrm{~A} 3$-fold increase in IL-1 $\beta$ was noticed after a conventional open colectomy than levels after a laparoscopic access in rats. ${ }^{29}$ Some investigators described lower concentrations of TNF- $\alpha$ after laparoscopy in different human surgeries. ${ }^{30}$ Nevertheless, Matsumoto and colleagues did not observe any difference among pure laparoscopy, hand-assisted or open nephrectomy in a pig model. ${ }^{11}$ In our study, both groups exhibited significantly elevated concentrations of IL-1 $\beta$ and TNF- $\alpha$ after surgery, with values being higher in the open group. On postoperative day 5, the cytokine levels had decreased to the preoperative levels in both groups, while levels in the open group remained slightly elevated. The results are also consistent with many previous studies. ${ }^{28-31}$

A variety of immunological abnormalities are always present in patients with malignant tumours, especially in regards to cell-mediated immunity; ${ }^{32}$ surgical trauma may aggravate the already present immune system imbalance by an intricate array of local and systemic physiologic responses. The mechanisms that regulate the host defense systems are complex and are associated with oncological results and prognosis. Functional activities of immunocompetent cells exert an important influence on the function of the immune system. In particular, T-lymphocytes play a primary role in the host defense against tumour cells trying to escape from immune surveillance, especially after surgery. The functional state of T-lymphocytes often depends on the percentage distribution of T-lymphocyte subsets, of which $\mathrm{CD}^{+}, \mathrm{CD}^{+}$, and $\mathrm{CD}^{+} \mathrm{T}$ cells predominate. ${ }^{33}$ The dynamic balance of $\mathrm{CD}^{+}: \mathrm{CD}^{+}$ratio, usually $1.3 \sim 2.1: 1$, can also indicate the state and capacity of cell-mediated immunity and the host's ability to inhibit tumour growth. ${ }^{34}$ Generally, the lower $\mathrm{CD} 4^{+}: \mathrm{CD} 8^{+}$ratio after surgery means cell-mediated immunological dysfunction in patients.

In our study after surgeries, T-lymphocyte subsets experienced dynamic changes in both groups, correlating with the extent of surgical trauma, duration of surgery and amount of blood loss. The $\mathrm{CD}^{+}$and $\mathrm{CD} 4{ }^{+} \mathrm{T}$ cells decreased in both groups, accompanied by an increase in $\mathrm{CD} 8^{+} \mathrm{T}$ cells in the open group, resulting in a decrease of the $\mathrm{CD}^{+}: \mathrm{CD}^{+}$ratio postoperatively in both groups. On day 5 after the surgery, only $\mathrm{CD}^{+}$and $\mathrm{CD}^{+}{ }^{+} \mathrm{T}$ cells in the retro-laparoscopy group returned to preoperative levels, suggesting a more rapid restoration of host immunity, which is further emphasized by the elevated $\mathrm{CD}^{+}: \mathrm{CD}^{+}$ratio. These findings may be potentially associated with an improved prognosis for the RCC patients. $^{35}$

In our study, the retro-laparoscopy included all the benefits of minimally invasive surgery for RCC patients. Although a decrease in immune competence occurred after both retro-laparoscopic and open nephrectomies, this competence was better preserved immediately after the retrolaparoscopic surgery when compared to the open approach. Theoretically, a better preserved immune function can prevent tumour seeding and therefore prevent the formation of distant metastases. Consequently, equal short to mediumterm follow-up results were achieved in both groups without the occurrence of any port site, wound or distant metastases or local recurrence. Additionally, there is little possibility that intraperitoneal metastases could occur without any injury to the peritoneum due to the retroperitoneal route.

\section{Conclusions}

The retroperitoneal laparoscopic radical nephrectomy can protect the host immunity by decreasing the cytokine responses and preserving the distribution of T-lymphocytes after surgery, which may indicate potential benefits over traditional invasive procedures. To further document these results, studies with longer follow-up and higher TMN stages, as well as additional laparoscopy researches on metastases, are needed.

\section{Competing interests: None declared.}

This paper has been peer-reviewed.

Acknowledgments: We thank Dr. Lan Zheng and Dr. Shuang Zhang for their technical support. 
Lu et al.

\section{References}

1. Clayman RV, Kavoussi LR, Soper NJ, et al. Laparoscopic nephrectomy: initial case report. J Urol 1991; 146:278-82.

2. Axel SM, Markus AK. Changing concepts in the surgery of renal cell carcinoma. World J Urol 2008;26:12733.

3. Ashok KH, Anup K, Narmada PG, et al. Oncologic outcome of 132 cases of laparoscopic radical nephrectomy with intact specimen removal for $\mathrm{T}_{1-2} \mathrm{~N}_{0} \mathrm{M}_{0}$ renal cell carcinoma. World J Urol 2007;25:619-26.

4. Davies MG, Hagen PO. Systemic inflammatory response syndrome. Br I Surg 1997;84:920-35.

5. Buunen $M$, Gholghesaei $M$, Veldkamp $R$, et al. Stress response to laparoscopic surgery: a review. Surg Endosc 2004;18:1022-8.

6. Lacy AM, Garcia-Valdecasas IC, Delgado S. Laparoscopy assisted colectomy versus open colectomy for treatment of non-metastatic colon cancer: a randomised trial. Lancet 2002;359:2224-9.

7. Jun-Hang L, Fang-Jian Z, Dan X, et al. Analysis of long-term survival in patients with localized renal cell carcinoma: laparoscopic versus open radical nephrectomy. World J Urol 2010;28:289-93.

8. Hewitt PM, ID SM, Kwok SP, et al. Laparoscopic-assisted vs open surgery for colorectal cancers: comparative study of immune effects. Dis Colon Rectum 1998;41:901-9.

9. Hildebrandt $U$, Kessler K, Pistorius $G$, et al. Granulocyte elastase and systemic cytokine response after laparoscopic assisted and open resections in Crohn's disease. Dis Colon Rectum 1999;42:1 180-6.

10. Perttila J, Salo M, Ovaska J, et al. Immune response after laparoscopic and conventional Nissen fundoplication. Eur J Surg 1999;165:21-8.

11. Matsumoto E, Margulis V, Tunc L. Cytokine response to surgical stress: comparison of pure laparoscopic, hand-assisted laparoscopic and open nephrectomy. J Endourol 2005;19:1140-5.

12. Myriam JC. Port site metastases. Am J Surgery 2004;187:705-12.

13. Octavio AC, Gonzalo V. Port site metastasis and tumour seeding in oncologic laparoscopic urology. Urology 2008; $71: 372-8$

14. Novitsky YW, Czerniach DR, Kaban GK, et al. Immunologic effects of hand-assisted surgery on peritoneal macrophages: comparison to open and standard laparoscopic approaches. Surgery 2006;139:39-45.

15. Bo P, Jun-hua Z, Hong L. Effect of retroperitoneal laparoscopic radical nephrectomy of renal carcinoma (nephroma) on perioperative cell immunity. J Endourol 2008;22:2161-4.

16. Morgan R, Gordon S, Jacques I, et al. Oncological risk of laparoscopic surgery in urothelial carcinomas. World J Urol 2009;:27:81-8.

17. Vincenzo F, Antonio G, Giacomo N, et al. Risk stratification and prognostication of renal cell carcinoma. World J Urol 2008:26:115-25.

18. Sido B, Teklote J, Hartel M, et al. Inflammatory response after abdominal surgery. Best Pract Res Clin Anaesthesiol 2004; 18:439-54.

19. Allendorf $J D$, Bessler $M$, Horvath $K D$, et al. Increased tumour establishment and growth after open vs. laparoscopic surgery in mice may be related to differences in postoperative T-cell function. Surg Endosc 1999:13:233-5.
20. Targorona $E M$, Pons $M J$, Balague $C$, et al. Acute phase is the only significantly reduced component of the injury response after laparoscopic cholecystectomy. World I Surg 1996;20:528-34.

21. Veenhof AAFA, Sietses C, von Blomberg BME. The surgical stress response and postoperative immune function after laparoscopic or conventional total mesorectal excision in rectal cancer: a randomized trial. Int J Colorectal Dis 2010;26:53-9.

22. Vittimberga FJ Jr, Foley DP, Meyers WC, et al. Laparoscopic surgery and the systemic immune response. Ann Surg 1998; 227: 326-34.

23. Biffl WL, Moore EE, Moore FA, et al. Interleukin-6 in the injured patient: marker of injury or mediator of inflammation? Ann Surg 1996;224:647-64.

24. Novitsky YW, Litwin DEM, Callery MP. The net immunologic advantage of laparoscopic surgery. Surg Endosc 2004;18:1411-9.

25. Edward D. Matsumoto, Vitaly M, Luffi T. Cytokine response to surgical stress: comparison of pure laparoscopic, hand-assisted laparoscopic, and open nephrectomy. J Endourol 2005;19:1140-5.

26. Landman J, Olweny E, Sundaram (P. Prospective comparison of the immunological and stress response following laparoscopic and open surgery for localized renal cell carcinoma. J Urol 2004;171:1456-60.

27. Sietses C, Beelen RH, Meijer S, et al. Immunologic consequences of laparoscopic surgery: speculation on the causes and clinical implications. Langenbeck's Arch Surg 1999;384:250-8.

28. Glaser F, Sannwald GA, Buhr HJ, et al. General stress response to conventional and laparoscopic cholecystectomy. Ann Surg 1995;221:372-80.

29. Kuntz C, Wunsch A, Bay F, et al. Laparoscopic colon resection in the rat: less immune and stress reaction and improved postoperative recovery. Surg Endosc 1996;10:568.

30. Lausten SB, Ibrahim TM, EI Sefi T. Systemic and cell-mediated immune response after laparoscopic and open cholecystectomy in patients with chronic liver disease. Dig Surg 1999;16:471-7.

31. Schietroma $M$, Carlei F, Franchi $L$, et al. A comparison of serum interleukin- 6 concentrations in patients treated by cholecystectomy via laparotomy or laparoscopy. Hepatogastroenterology 2004;51:1595-9.

32. Kuss I, Hathaway B, Ferris RL, et al. Imbalance in absolute counts of T lymphocyte subsets in patients with head and neck cancer and its relation to disease. Adv Otorhinolaryngol 2005;62:161-72.

33. Robertson MJ, Schacterle RS, Mackin GA, et al. Lymphocyte subset differences in patients with chronic fatigue syndrome, multiple sclerosis and major depression. Clin Exp Immunol 2005; 141:326-32.

34. Gang L, Hong R, Xue-Jun S. Distribution of natural killer cells and T-lymphocyte subsets in peripheral blood, gallbladder cancer and surrounding tissue. Hepatobiliary Pancreat Dis Int 2007;6:81-6.

35. Charles $E$, Christine $G$, Devinder K. Impact of surgery on immunologic function: comparison between minimally invasive techniques and conventional laparotomy for surgical resection of colorectal tumours. Am J Surgery 2009;197:238-45.

Correspondence: Dr. Fan Tianyong, Department of Urology, West China Hospital, Sichuan University, Chengdu610041, China; fax: +86-028-85422451; fanlaoshiy|@163.com 